\title{
Acontecimentos Significativos na História Geracional e sua Relação com Somatizações na Família ${ }^{1}$
}

\author{
Aline Vilhena Lisboa ${ }^{2}$ \\ Universidade Estácio de Sá \\ Terezinha Féres-Carneiro \\ Pontifícia Universidade Católica do Rio de Janeiro
}

\begin{abstract}
RESUMO - Este relato de pesquisa busca estabelecer algumas relações entre somatizações e história familiar. Propõe investigar a somatização, analisando acontecimentos significativos na família. Utilizou-se a investigação qualitativa, realizando entrevistas semidirigidas com dez famílias. Recorreu-se à análise de conteúdo de relatos que estariam subjetivamente associados ao contexto de algumas doenças. Verificou-se que a doença compreende uma das expressões da violência familiar. A repetição de comportamentos conflituosos e violentos entre gerações e a instabilidade afetiva demonstram o cotidiano destas famílias e provocam um desgaste afetivo. As somatizações surgem como representação da invasão do outro, da dificuldade de expressão de sentimentos e do desconhecimento das demandas afetivas. Este estudo pretende contribuir para ações mais efetivas do psicólogo na prevenção primária à saúde da família.
\end{abstract}

Palavras-chave: história familiar, acontecimentos significativos, somatização, violência, conflitos

\section{Significant Events in Generational History and Their Relations to Somatizations in the Family}

\begin{abstract}
This research report aims to present some of the relations between somatizations and family history. It proposes to investigate somatization by analyzing significant events in the family. Semi-structured interviews with ten families were conducted in the context of a qualitative investigation approach. Content analysis was realized of the reports that were subjectively associated to the context of a number of diseases. It was observed that the disease encompasses one of the expressions of family violence. The repetition of conflicting and violent behaviors between generations, and the affective instability, demonstrate the daily routine of these families, and they provoke affective wear. The somatizations arise as a representation of the invasion of another person's life, as the difficulty of expressing feelings, and as the unawareness of affective demands. The present study intends to contribute to more effective actions coming from the psychologist in the primary prevention of family health.
\end{abstract}

Keywords: family history, significant events, somatization, violence, conflicts

Nos últimos tempos, a família tem sido assunto de inúmeros debates envolvendo questões sobre os novos arranjos e as diferentes formas de relacionamento e de convivência. Na última década, também se intensificaram as intervenções de profissionais especializados em família atuando no contexto clínico e social em situações de doenças, de risco e de conflito.

As questões familiares possuem interfaces de amplo espectro, contribuindo continuamente para mudanças significativas na sociedade, podendo influenciar o sofrimento do sujeito. Na mesma direção, a família apresenta diversas modalidades intersubjetivas, endossando novas formas de subjetivação traduzidas em surpreendentes e, às vezes, enigmáticos quadros de doenças.

A saúde da família se constrói primeiramente com base nas relações vinculares primárias, onde são observados os investimentos afetivos dos membros em relação aos projetos de vida e à busca de satisfação e bem-estar. Observa-se,

1 Apoio: Capes

2 Endereço para correspondência: Alameda José Cristiano Neto, 552, Riviera, Macaé, RJ, Brasil. CEP: 27.935-370.E-mail: alinevlisboa@ ig.com.br entretanto, que nem sempre esta construção ao longo da vida familiar acontece de maneira satisfatória e saudável. Estudos desenvolvidos por vários pesquisadores (Féres-Carneiro, 2003; Macedo, 2008; Osório \& Valle, 2009, 2011; Ruiz Correa, 2000) apontam preocupações e impasses diversos que colocam em questão o lugar da família na estruturação psíquica, na saúde e na intermediação do sujeito com outros grupos. Nas duas últimas décadas, estudos sobre saúde da família (Chazan, 2004; Lisboa, Santos, Bassoli, Paiva, \& Fernandes, 2011; Mello Filho \& Burd, 2010) demonstram que o universo familiar deve ser respeitado pelas suas relações e história na construção de sentidos de saúde pelo sujeito.

Assim, este trabalho tem como objetivo geral estabelecer algumas relações entre somatizações apresentadas pelos membros da família e a história familiar. Possui também um objetivo secundário voltado para as possíveis intervenções clínicas e sociais preventivas com famílias, lançando desafios para novas estratégias de acolhimento e de trabalho em relação ao sofrimento associado às doenças ao longo do tempo. Acredita-se que a escuta da história geracional, as transformações impostas pelo cotidiano e as demandas subjetivas internas podem proporcionar melhor compreensão 
sobre a influência da família na representação da saúde do sujeito.

Trazemos para discussão a somatização como um processo constituído também pela intersubjetividade familiar, amalgamada por um contexto cultural particular. Desse modo, a reflexão sobre o processo de somatização à luz da concepção da psicossociossomática se faz necessária a fim de que possamos visualizar este processo psicocultural na família, a partir de investimentos afetivos em descompasso com representações, que engessam a capacidade de expressão e de elaboração do grupo. Do ponto de vista clínico, compreendemos que a somatização na família é uma construção intersubjetiva que acontece de maneira silenciosa e aniquiladora, minando a capacidade de a mesma se manter saudável, à medida que há um acúmulo de acontecimentos significativos não elaborados, ou não superados em sua história.

Desse modo, este relato de pesquisa pretende avaliar em que medida os adoecimentos somáticos envolvem uma colusão de acontecimentos significativos na história familiar. Acontecimentos significativos ocorridos na história de vida da família podem ser vivenciados e interpretados como sofrimentos cumulativos, e a somatização em alguns membros caracteriza-se como a falta de reconhecimento deste sujeito sobre a história dos acontecimentos, assim como por aquilo que não se expressa sobre eles. Objetivamos, portanto, apresentar parte das histórias geracionais das famílias que são circunscritas por fatos significativos, principalmente por circunstâncias de doenças e violência, vivenciadas durante o desenvolvimento dos membros somatizantes atuais.

\section{A Família como Espaço Intersubjetivo e Intergeracional de Acontecimentos Significativos}

De acordo com nossas concepções, a família compreende o centro de relações interdependentes, onde os sujeitos irão demandar sempre a presença do outro desde o início de suas vidas. Estas relações sofrem transformações ao longo do tempo, de acordo com acontecimentos internos e externos. A resposta da família às transformações pode demonstrar maturidade diante das mudanças ou uma realidade de conflitos intensos e persistentes, de difícil negociação, que podem ficar velados por muito tempo e passados de geração a geração. Os efeitos destas situações permanentes e duradouras chegam a tomar proporções catastróficas para as relações internas culminando, portanto, no comprometimento do grupo em sustentar-se afetivamente.

Além de a família operar na estruturação do psiquismo do sujeito, funcionando como continente de apoio e possuidora de uma história singular (Ruiz Correa, 2000), é preciso pensar que ela se apresenta como um grupo que pensa por si e que constrói suas próprias leis e referências. Em todo o percurso de sua história, a família é permeada por circunstâncias significativas, colocando os membros em constante e simultâneo estado de atenção, satisfação, tensão e ansiedade. Os recursos psicológicos para o enfrentamento e adaptação às demandas externas e internas repercutem de maneira diferente na saúde de cada membro.
Carter e McGoldrick (1995) acreditam que os eventos que circunscrevem cada fase de vida do grupo possuem um efeito continuado e agem por um grande período de tempo sobre o desenvolvimento de todos os membros. Nessa direção, sustentamos a ideia de que a capacidade e os recursos utilizados pela família nos períodos de aquisições e de transformações se apóiam na sua capacidade de holding (Winnicott, 1993). Acredita-se que o grupo deve trabalhar para garantir a existência de um holding familiar extenso e continuado em todas as suas fases de vida, na forma de um continente de apoio psíquico, cuja função de proteção e de contenção das demandas subjetivas possa assegurar a continuidade de seu desenvolvimento em cada acontecimento significativo.

Podemos pensar acontecimento significativo sob duas perspectivas. Primeiramente, como todo ritual de passagem e fases de constituição e desenvolvimento da família como escolha conjugal, casamento, nascimento dos filhos e envelhecimento. Estas fases interferem na produção subjetiva e intersubjetiva dos modos de expressão e de representação do grupo. A segunda perspectiva mostra o acontecimento significativo como uma situação inesperada de doença, morte, ou situação que fuja ao controle do sujeito e do grupo. Postulamos que uma das grandes dificuldades em relação aos acontecimentos significativos na família está na maneira pela qual a mesma encara e enfrenta estes movimentos de transição e de transformação. Muitas vezes, ocorre um embate geracional que se reflete nas formas de subjetivação e vinculações.

Para Ruiz Correa (2002), o campo intersubjetivo familiar apresenta-se como um espaço de ligação e de transformação de heranças e acontecimentos, que provoca uma complexidade de inscrições subjetivas. A intersubjetividade familiar compreende uma interface dos aspectos singular-plural, ou seja, sujeito-grupo com os materiais transmitidos pelas gerações, onde o discurso de todos influencia na produção subjetiva de um e de todos ao mesmo tempo. Assim, do ponto de vista da produção intersubjetiva familiar, podemos dizer que o casal e a família se transformam com os problemas domésticos e com as demandas sociais conjugando, simultaneamente, o espaço intersubjetivo no duplo aspecto. Sobreviver a essa movimentação interna constante, de maneira mais saudável, se deve à condição do grupo de se constituir e de se manter como apoio psíquico. Podemos pensar que a construção da saúde da família consiste em administrar as necessidades materiais e afetivas, além de equilibrar o jogo ambivalente, e ao mesmo tempo alternativo, entre a presença e a distância física e psíquica, respectivamente.

$\mathrm{Na}$ somatização, acreditamos que o sujeito possa apresentar uma limitação de sua capacidade de gerenciar situações conflituosas e de tensão, em consequência de uma combinação de fatores psíquicos adversos, gerando possíveis estados de ansiedade, estresse, ou depressão. Por isso, damos ênfase à análise dos processos psíquicos, sociais e culturais que antecedem a somatização. Desse modo, podemos pensar que a somatização compreenderia um processo contínuo, cumulativo e um dos destinos das situações conflituosas familiares. 


\section{A Somatização e sua Interface com a Intersubjetividade Familiar}

Estudos e conceitos sobre somatização possuem controvérsias e abrangem um campo vasto de teorias com embasamento médico, psicológico, cultural e social, muitas vezes mais divergentes que complementares. Destacamos que a somatização, sob o ponto de vista da psicossomática psicanalítica (Marty, 1998), compreende um processo progressivo e desorganizado da forma de o sujeito operar psiquicamente as suas defesas e investimentos afetivos. Sob o aspecto psicossociossomático (Helman, 2003), a somatização apresenta particularidades psicoculturais que influenciam na maneira de compreender e de tratar a doença.

Ao dialogarmos com Lipowski (1988) e Coelho e Ávila (2007), verificamos que somatização compreende um conceito amplo e que exige uma olhar transdisciplinar sobre o sujeito. Entretanto, Lipowski, apesar de afirmar que a tendência de o paciente comunicar e expressar algum sintoma somático, sem comprovação clínica do mesmo, compõe um quadro de somatização, o autor não considera que todas as doenças são somatizações e que esta se manifesta geralmente em pacientes com transtornos psiquiátricos. Os estudos de Coelho e Ávila apontam que a somatização pode estar ou não em comorbidade com transtornos psiquiátricos e a necessidade de encontrar uma única definição para o termo limita a construção de uma visão transdisciplinar do mesmo. Este fato nos permite considerar a dimensão intersubjetiva familiar no processo de adoecimento do sujeito.

Desse modo, queremos dizer que podemos pensar a somatização como um processo biopsicossocial integrado, contínuo e cumulativo, que está em constante movimento de organização e desorganização com o meio, tanto psíquico quanto social e cultural. Esta movimentação tem como um grande balizador o contexto familiar, uma vez que este grupo apresenta uma história com situações significativas adversas que passam a compor fatores antecedentes de um processo de somatização. Sob uma perspectiva do funcionamento psíquico, destacamos que a somatização representa toda a doença que o sujeito produz no corpo, seja com comprovação clínica ou não, pois, de algum modo, o psiquismo opera em conformidade com um conjunto de movimentações, em defesa contra exigências internas e externas as quais o sujeito não consegue absorver e gerenciar satisfatoriamente.

Diferentemente do processo de conversão, apontado por Freud (1896/2000, 1893/2000), a somatização não só abrange uma desorganização psíquica entre as esferas consciente, pré-consciente e insconsciente como se refere à utilização de outras atividades de defesa do sujeito levadas ao extremo, além da condensação e do deslocamento verificadas inicialmente pelo autor. Alguns mecanismos psíquicos, forjados pelo sujeito para manter o conflito distante, voltamse contra o mesmo de maneira a invalidar os seus próprios recursos diante de algum acontecimento. Mecanismos de defesa como a negação, a projeção e a introjeção são levados em um nível de operação, às vezes, avassalador, engessando as movimentações pulsionais do sujeito. O congelamento ou congestionamento da capacidade psíquica de transformar as representações de coisas, de gerenciá-las e elaborá-las em expressões verbais, podem comprometer o trabalho psíquico do sujeito de manter-se em discurso com o próprio corpo.

De acordo com Marty (1998, 1980), do ponto de vista psíquico, compreendemos a somatização como uma dissociação entre o trabalho psíquico e o corpo de maneira que o primeiro enfraquece ou perde gradativamente sua capacidade de ligação, de sintonia com as exigências biológicas e sociais. Com base nessa postulação, avançamos no entendimento de que os aspectos socioculturais do adoecimento incluem acontecimentos significativos que fizeram parte da história da família e que cada sujeito interpretará à sua maneira. Estes acontecimentos que antecedem ao adoecimento, ou acontecem simultaneamente ao período do adoecimento, podem estar amalgamados ao impacto provocado pelos mesmos na vida do sujeito, de maneira a levá-lo a uma suspensão da capacidade de elaboração e a um desgaste ou empobrecimento de seu investimento afetivo e verbal. Os impactos causados por situações significativas, como casamentos, nascimentos, mortes, separações, causam efeitos pontuais e/ou continuados na produção intersubjetiva familiar. Desse modo, a questão destacada neste trabalho mostra até que ponto os acontecimentos significativos da história familiar representariam elementos cumulativos, condicionantes e construtores de adoecimento somático.

\section{A Relação de Acontecimentos Significativos com Somatizações na Família}

Entende-se por acontecimentos significativos todo evento, ritual de passagem ou fato marcante na vida do sujeito e da família que exija mudanças e adaptações. Eles podem significar momentos dolorosos tanto quanto prazerosos, além de compreender uma construção significativa sobre um fato sem corresponder à realidade concreta do mesmo. Geertz (1989) relata que o acontecimento possui muito mais sentido na forma como o sujeito fala sobre o mesmo, através da expressão de sentimentos e de comportamentos, do que o acontecimento em si. Isso significa que um fato nem sempre terá o mesmo impacto para os membros da família.

Em situação de conflito e até de violência, a família coloca em risco a integridade e a saúde de seus membros, por encontrar dificuldades de reconhecer, pensar e elaborar o próprio acontecimento. Nesta situação, os sujeitos se encontram suscetíveis às intempéries das relações, onde todos se tornam vítimas da própria falta de conhecimento e representação de seus anseios, medos e dúvidas. Assim, acreditamos que os acontecimentos considerados conflituosos e violentos para a família podem induzir novas formas de intersubjetivação, cuja vulnerabilidade das relações afetivas coloca em risco a saúde de seus membros.

Já dizia Freud (1930/1978) que uma das fontes de sofrimento do homem está na dificuldade e, muitas vezes, inadequação na convivência do mesmo com o outro. Assim, dizemos que uma parte do desenvolvimento da doença se encontra na incapacidade de o sujeito reconhecer o seu próprio limite no domínio de si sobre as dimensões e intensidade dos acontecimentos familiares e das relações com a família. 
Como fatores de risco para o adoecimento somático, os conflitos constantes e as situações de violência geram vivências permanentes de tensão e de estresse na família. Nossa afirmativa se encontra respaldada em Castiel (1994), que aponta a existência de elementos antecedentes a uma situação de estresse e de doença no sujeito, pertencentes à história familiar desestruturante do vínculo e do lugar do sujeito. Para o autor, o encontro desses elementos tanto psicológicos quanto sociais configura a base norteadora de um processo de adoecimento. Dessa forma, em relação aos elementos e às circunstâncias significativas que antecedem uma somatização, há ainda outros que se circunscrevem às situações de violência, como o uso crônico de álcool, o desemprego, as mudanças geográficas e culturais, as perdas e as separações.

Em várias circunstâncias, pensamos que a família se depara com "nós" atados pela própria história, cuja natureza inacabada de suas próprias ações interfere nas modalidades de subjetivação das gerações futuras. A partir da nossa experiência clínica com famílias, percebemos que poucos são aquelas que reconhecem o inacabado, à medida que utilizam seus potenciais a favor da própria elaboração psíquica e do amadurecimento emocional. A existência do desconhecido, senão a resistência ao mesmo, disseminada num ambiente familiar, representaria a dificuldade de acesso ao potencial psíquico de todos os membros envolvidos.

Essa condição torna a família refém da ignorância de sua própria história, capturada pelas confusões sucessivas e repetitivas, que são representadas em um distanciamento entre o que é conhecido e sentido, e o que é pensado e dito. Isto permite que os sujeitos se interponham num jogo emaranhado entre o que pertence ao grupo, o que pertence a cada um deles e o que pertenceu à história parental anterior. Assim, acreditamos que, a todo instante, a subjetividade e a alteridade são colocadas à prova, num movimento retórico, em que a subjetividade se compromete com o intersubjetivo também comprometido, tanto com elementos que impulsionam o desenvolvimento do grupo, quanto com fatores desestruturantes.

De acordo com Ruiz Correa (2007), na clínica de família em situação de violência há uma expressão sintomática em forma de falha da função de continente e de ambiente psicológico, que se traduz por uma patologia herdada em relação ao continente familiar de outras gerações. As queixas clínicas trazidas por familiares acerca dos comportamentos dos sujeitos violentos mostram que o grupo tem extrema dificuldade de compreender o motivo da situação e, muito menos, a razão pela qual os sujeitos se dispõem a isso.

Pensamos na existência de um abismo entre acolhimento e entendimento, entre demanda e necessidade, entre escoamento das excitações psíquicas e satisfação das mesmas na psicodinâmica de famílias com história cumulativa de conflitos e de violência. Supomos que esses abismos influenciam no processo de adoecimento de seus membros. No fluxo desse pensamento, há fatores desestruturantes, como os citados anteriormente, que materializam-se em várias formas de adoecimentos, retratando uma desconfiguração do produto gerado pelo grupo. O corpo adoecido é um misto de ações, comportamentos, representações e fantasias do sujeito em descompasso com a falta de conhecimento da história e a falta da capacidade de prover e sustentar as necessidades afetivas dos membros da família.

Percebe-se ainda que alguns acontecimentos significativos como o nascimento de um filho, casamento, separação, saída dos filhos de casa e morte, por exemplo, configuram um estopim para o desencadeamento de situações conflituosas e veladas no grupo. Em consonância com Freud (1910/1978), acreditamos que o sujeito rumina em sua mente as reminiscências deixadas pelas excitações soltas e sem representação dessas mudanças, que se reatualizam em momentos diferentes no futuro, diante de situações semelhantes ou sem importância, aparentemente.

Assim, do ponto de vista intersubjetivo, consideramos que a capacidade de adaptação e elaboração da família diante destas mudanças permanece também em suspensão, em situações de extremo conflito e violência. As excitações psíquicas soltas, ou melhor, as demandas sem representação, são consideradas como uma violência, um ataque à condição de pensar e elaborar do grupo. A família lança recursos de defesa como a negação e a repetição, mas que operam a favor de uma censura que engessa a circulação da palavra e dos investimentos afetivos.

Encontramos parte desta fundamentação em Déjours (1989), que mostra as excitações soltas como representantes de uma violência ao psiquismo, a partir da falta de suporte/ contenção e de simbolização do sujeito. O autor cita ainda que a própria somatização é um caminho encontrado pela psique para fins de escoamento das excitações invasivas. Como considera a somatização um processo de difícil predição, o autor revela que ela servirá para uma elaboração a posteriori das excitações invasivas ou violentas. As somatizações serão "simbolizadoras", pois permitirão novas ligações psíquicas, ativando a capacidade de o sujeito representar coisas. Assim, o adoecer de um membro é o momento oportuno para que a família recupere a capacidade de representar acontecimentos significativos em sua história geracional.

\section{Método}

\section{Participantes}

O trabalho de campo foi realizado em parceria com uma universidade pública federal e com uma unidade de atenção básica à saúde de uma cidade do interior de Minas Gerais, durante os anos de 2007, 2008, 2009 e 2010. Expusemos três critérios de seleção de famílias para as equipes de Saúde da Família: $1^{\circ}$ - famílias que habitavam na região; $2^{\circ}$ - famílias que possuíam mais de um membro com qualquer tipo de doença e $3^{\circ}$ - famílias que habitavam na mesma casa ou no mesmo terreno. Foram entrevistadas dez famílias, 42 pessoas ao todo, encaminhadas pelos agentes de saúde e pela assistente social.

\section{Procedimento}

Foi desenvolvida uma investigação qualitativa (Turato, 2003), utilizando entrevistas semanais domiciliares com 
a presença do pesquisador-coordenador e de um alunoassistente do curso de Psicologia da universidade pública. Cada família recebeu uma numeração na análise e para cada uma foram realizadas quatro visitações em domicílios, durante um mês, por dois pesquisadores. A primeira entrevista foi dirigida e as três entrevistas restantes foram semidirigidas. Foi utilizado um questionário para levantamento de dados socioeconômicos e culturais na primeira entrevista, juntamente com a confecção de um genograma (McGoldrick \& Gerson, 1995) pela equipe de pesquisa, para mapear as doenças das famílias até duas gerações. Um roteiro contendo perguntas relacionadas à história geracional familiar foi utilizado nas últimas três entrevistas.

As entrevistas foram gravadas com autorização dos participantes, depois que o termo de consentimento livre e esclarecido era lido e assinado. Com base na Resolução 196/96 do Conselho Nacional de Saúde e com a aprovação do Comitê de Ética da universidade onde o curso de doutorado foi realizado, esta pesquisa foi desenvolvida em conformidade com as normas da referida resolução, e não ofereceu risco aos sujeitos envolvidos. Consideramos o encaminhamento de participantes para atendimento psicológico, caso houvesse um grau maior de mobilização de algum conteúdo não trabalhado pela família.

Com base nas postulações de Bardin (2007), realizamos uma análise do conteúdo do material transcrito sob duas perspectivas: uma pela análise de conteúdo intrafamiliar e outra interfamiliar. A análise das informações partiu do levantamento de categorias temáticas que surgiram na associação entre "adoecimento e circunstâncias que antecediam ou ocorriam simultaneamente na história familiar". Os dados coletados pelo genograma e pelo questionário serviram para traçar um perfil das famílias.

\section{Resultados}

O questionário de informações socioeconômicos e culturais indicou que $85 \%$ das famílias entrevistadas pertencem à classe média baixa, com uma população predominantemente adulta em atividade profissional. Após montagem do genograma, foi observado que a

Tabela 1. Famílias e Conteúdos Temáticos sobre Acontecimentos Significativos

\begin{tabular}{|c|c|c|c|c|c|}
\hline $\begin{array}{l}\text { Famílias/Categorias } \\
\text { temáticas principais }\end{array}$ & Doença & Violência & Conflitos & Perda & Satisfação na vida \\
\hline Fam1 & $\begin{array}{l}\text { sofrimento no período } \\
\text { da doença da filha } \\
\text { (câncer no estômago }\end{array}$ & $\begin{array}{l}\text { convivência com o } \\
\text { marido alcoolista }\end{array}$ & NR & $\begin{array}{l}\text { morte de dois filhos } \\
\text { durante e após o parto }\end{array}$ & Maternidade \\
\hline Fam2 & NR & $\begin{array}{l}\text { abandono e rejeição } \\
\text { parental e violência } \\
\text { física parental }\end{array}$ & $\begin{array}{l}\text { falta de apoio familiar } \\
\text { no desenvolvimento } \\
\text { pessoal }\end{array}$ & NR & NR \\
\hline Fam3 & $\begin{array}{l}\text { preocupação com a } \\
\text { doença psiquiátrica } \\
\text { da filha }\end{array}$ & $\begin{array}{l}\text { convivência com o } \\
\text { marido alcoolista e } \\
\text { violento }\end{array}$ & NR & NR & NR \\
\hline Fam4 & $\begin{array}{l}\text { preocupação com a } \\
\text { doença do marido, } \\
\text { depois da morte do } \\
\text { filho }\end{array}$ & NR & $\begin{array}{l}\text { mudança de rotina } \\
\text { da família a partir do } \\
\text { crescimento dos filhos }\end{array}$ & $\begin{array}{l}\text { morte precoce do filho } \\
\text { e da mãe da mãe }\end{array}$ & NR \\
\hline Fam5 & $\begin{array}{l}\text { Convivência com a } \\
\text { mãe alcoolista. }\end{array}$ & $\begin{array}{l}\text { convivência com o pai } \\
\text { violento e alcoolista e } \\
\text { a mãe alcoolista }\end{array}$ & migração para a cidade & $\begin{array}{l}\text { morte recente da mãe e } \\
\text { de duas irmãs. }\end{array}$ & $\begin{array}{l}\text { nascimento da neta e } \\
\text { vida na roça }\end{array}$ \\
\hline Fam6 & $\begin{array}{l}\text { sofrimento pela } \\
\text { doença neurológica } \\
\text { irreversível da mãe }\end{array}$ & $\begin{array}{l}\text { rejeição do casamento } \\
\text { do filho }\end{array}$ & NR & NR & $\begin{array}{l}\text { maternidade e } \\
\text { momentos bons em } \\
\text { família }\end{array}$ \\
\hline Fam7 & NR & NR & NR & NR & $\begin{array}{l}\text { maternidade e } \\
\text { momentos bons em } \\
\text { família }\end{array}$ \\
\hline Fam 8 & $\begin{array}{l}\text { sofrimento e desgaste } \\
\text { durante os cuidados } \\
\text { com o marido doente e } \\
\text { falecido }\end{array}$ & $\begin{array}{l}\text { convivência com o } \\
\text { marido alcoolista } \\
\text { e violento. Brigas } \\
\text { violentas entre os pais. }\end{array}$ & $\begin{array}{l}\text { conflitos entre pais e } \\
\text { filhos }\end{array}$ & morte da filha no parto & NR \\
\hline Fam9 & $\begin{array}{l}\text { sofrimento pela } \\
\text { doença neurológica } \\
\text { progressiva do marido }\end{array}$ & rejeição filial & $\begin{array}{l}\text { aposentadoria do pai } \\
\text { e falta de tolerância } \\
\text { dos membros com o } \\
\text { mesmo }\end{array}$ & NR & $\begin{array}{l}\text { viagem ao estrangeiro } \\
\text { e vida na roça }\end{array}$ \\
\hline Fam10 & $\begin{array}{l}\text { sofrimento e desgaste } \\
\text { com cuidados } \\
\text { contínuos da doença } \\
\text { neurológica do filho }\end{array}$ & $\begin{array}{l}\text { prisão do filho mais } \\
\text { velho por droga e furto }\end{array}$ & NR & NR & NR \\
\hline
\end{tabular}

Nota: Os conteúdos temáticos aparecem em ordem decrescente em quantidade de vezes de apresentação no discurso das famílias. $\mathrm{NR}=$ Nenhum relato. 
hipertensão, o diabetes, os problemas cardíacos e as doenças gastrointestinais apresentam-se como as doenças mais frequentes nos membros adultos e repetem em duas gerações. Constatamos, em algumas famílias, algumas doenças associadas a outras. Há quatro casos de hipertensão, na família 8, associados ao diabetes. Algumas doenças cardiovasculares e gastrointestinais nas famílias 1, 2, 5, 6, 7 e 8 estão associadas ao uso crônico de álcool. Os problemas cardíacos nas famílias 1, 2, 5, 8 e 9 estão associados ao fumo e aos problemas da menopausa.

Colocamos em um quadro os principais acontecimentos ao longo da história da família em conformidade com a opinião geral do grupo familiar. Os acontecimentos foram classificados por ordem decrescente em número de ocorrência nos relatos dos entrevistados. O quadro aponta primeiramente "Doença" e assim sucessivamente as situações de "Violência", "Conflitos intensos", "Perda" e "Satisfação na vida". Classificamos a temática "Doença" para as doenças graves e crônicas de algum membro, durante a vida em família, e sua relação com o adoecimento atual do membro. As situações de "violência" compreendem as brigas intensas, surras, abandono e prisão. Os "Conflitos" designam problemas de convivência entre gerações, falta de adaptação por mudança e falta de apoio no desenvolvimento de alguns membros. As "perdas" se referem às mortes de parentes e filhos e a temática "Satisfação na vida" aponta os acontecimentos que causaram satisfação e felicidade para o grupo familiar. As famílias que não relataram nenhum fato receberam a sigla NR (nenhum relato).

Conforme tabela em anexo (Tabela 1), podemos observar que acontecimentos relacionados às situações de doença e violência se destacam em maior número, aparecendo em oito e sete famílias respectivamente. As famílias 1, 5, 8 e 9 apresentam mais de três relatos de acontecimentos significativos na história no período anterior das doenças ou durante as doenças repentinas de algum membro, sendo que em todas as famílias constatamos fatos como lembranças ou ideias de sofrimento dos membros diante de momentos de mudanças e de aquisições no seu percurso de vida. As situações mais marcantes, associadas ao período de adoecimentos de alguns membros, estão relacionadas à convivência duradoura com um membro doente e ao enfrentamento da própria doença pelo sujeito, exigindo uma adaptação significativa de todos.

Observamos, entretanto, que na família 4, as doenças do marido, diabetes e hipertensão, surgiram após a morte do filho de 15 anos por causa de um acidente de carro. Na família 5, a perda recente da mãe doente afetou emocionalmente a saúde de três irmãs. Uma faleceu dois anos depois de câncer. As outras irmãs desenvolveram diabetes e câncer de mama respectivamente. Em consequência de uma convivência com cônjuges ou filhos doentes ou transgressores, as famílias 1, 2, $3,5,8,9$ e 10 passaram por privações financeiras e sociais e por um intenso desgaste emocional. As somatizações crônicas como asma, dermatites, hipertensão e diabetes são mais presentes e persistentes nestas famílias. $\mathrm{O}$ fato significativo de maior repetição nas famílias, associado à doença, está na convivência com um membro alcoolista, como aparece nas famílias 1, 3, 5 e 8, que foi considerada pelos membros como geradora de inúmeros acontecimentos violentos.
As mudanças geográficas e internas na família foram compreendidas também como provocadoras de conflito e ameaça para a rotina das famílias 4, 5 e 9. Para as famílias 2, 6 e 8, as situações de mudança no ciclo familiar, como o crescimento dos filhos e casamento de filhos, geravam situações de conflitos intensos, violência e doenças. Em duas famílias, 5 e 9, a vida na roça mostrou maior satisfação que a vida na cidade, o que acarretou problemas de adaptação e convivência com outros grupos sociais. Por outro lado, observamos que nas famílias 1, 5, 6 e 7 a maternidade significou renovação dos projetos pessoais e familiares e compreendeu o assunto de maior destaque dentro da temática satisfação. Em especial, a família 7 se destacou por associar acontecimentos significativos com situações prazerosas, enfatizando a boa convivência familiar.

\section{Discussão}

De acordo com os relatos das famílias, a grande maioria associa as doenças atuais com a história familiar de convivência com outros membros doentes e violentos. Os conflitos e perdas aparecem em uma posição não tão significativa na associação direta realizada pelos membros, mas foram interpretados pelos pesquisadores como acontecimentos colaboradores para os adoecimentos nas famílias. Observamos que alguns acontecimentos satisfatórios surgiram em meio à temática do adoecimento, apontando para relatos opostos aos dados fornecidos por outras famílias.

Em decorrência de acontecimentos intensos e contínuos de doença e violência, verificamos que as relações familiares se encontram desgastadas com menor tolerância diante de qualquer outro movimento externo em relação à convivência social, projetos de trabalho e de estudo nas circunstâncias dos adoecimentos atuais.

Conforme Ruiz Correa (2002, 2000), a família representa um espaço de expressão e transformação das heranças geracionais e de construção de uma identidade. Nos casos estudados, observamos que o acúmulo de acontecimentos significativos, sentidos principalmente como sofrimento, interfere na convivência entre os membros, assim como na capacidade de produção subjetiva dos mesmos.

Podemos dizer, portanto, que a identidade familiar é construída a partir de situações que não endossam a capacidade e o potencial psíquico e emocional dos membros, fragilizando as condições futuras de intersubjetivação. As situações de violência e de conflitos refletem, respectivamente, na incapacidade de compreensão das necessidades e na falta de apoio às demandas de cada membro pelas famílias. Sendo assim, a intersubjetividade familiar (Ruiz Correa, 2002) também é constituída a partir do acúmulo de situações significativas de sofrimento.

Os relatos marcantes sobre rejeição parental e filial aparecem nas famílias 2, 6 e 9, em associação com doenças e internações intermitentes e uso indiscriminado e excessivo de medicação. As situações de doença e violência, vividas pelas gerações anteriores, ressoam nas atitudes de rejeição parental ou filial, na forma de indiferença sobre as necessidades afetivas de outros. Verificamos que, durante o período 
de desenvolvimento familiar, estas situações familiares dificultam a constituição de um holding (Winnicott, 1993), colaborando para que as repetições destas mesmas situações aconteçam nas futuras gerações.

As perdas aparecem em quatro famílias e foram relatadas sob uma atmosfera de muito sofrimento e falta de superação. Os membros discursavam de maneira confusa, com falas reticentes e sentimentos de mágoa, impotência e revolta. Encontramos na família 1 maior resignação e conformidade diante das perdas. Nas demais famílias havia certo rancor traduzido em comportamentos irritados, impacientes e até de pouco caso. A partir das contribuições de Marty $(1998,1980)$ e articulando com o universo familiar, a somatização pode ser compreendida como o sentido dado aos acontecimentos significativos da história familiar, na forma de defesas intrafamiliares necessárias contra situações que não foram expressadas e elaboradas pelos membros. A somatização não compreende somente uma maneira cultural de a família conceber e tratar o adoecimento, conforme afirma Helman (2003), mas também como a capacidade de expressão de sua história afetiva.

Diferentemente do que nos diz Lipowski (1988), a somatização não necessariamente está acompanhada por transtornos psiquiátricos, mas evidenciamos que há movimentações afetivas e pulsionais em defesa das demandas geracionais. Castiel (1994) afirma a existência de elementos antecessores ao adoecimento, que pudemos observar neste estudo nas formas de convivência com doenças crônicas e violência. Sendo assim, podemos considerar que a ansiedade e a depressão aparecem como produtos dos sentimentos de mágoa, raiva e rejeição que se acumulam e configuram situações de risco, que antecedem os quadros de doenças reativas e crônicas manifestadas por alguns membros na família.

\section{Considerações Finais}

Em cada história familiar, um sujeito adoece. A relação entre adoecimento e história familiar é muito próxima. Os acontecimentos significativos na história das famílias estudadas apresentam-se de maneira cumulativa e duradoura em relação à convivência com membros doentes e violentos, ao longo da história familiar, como no relato de M. sobre a filha na família 2, "Ela foi internada, porque ela não tava alimentando. ...nunca tive e não tenho até hoje apoio da minha família pra nada...Nosso Deus, minha mãe me batia demais!"

Os acontecimentos significativos antecedem os adoecimentos e/ou se apresentam simultaneamente com o adoecer repentino. Em geral, os acontecimentos são negados e vivenciados de forma cumulativa, provocando um desinvestimento afetivo progressivo nos laços familiares e, consequentemente, em alguns casos, o aparecimento de somatizações crônicas e reativas a estas situações. O adoecimento pode representar uma das formas de expressão da dinâmica intersubjetiva do sujeito, significando um representante de uma história de convivências conflituosas e até violentas.

Os acontecimentos significativos configuram o contexto histórico para o surgimento das somatizações na família.
A doença é uma das tentativas de situar e integrar as reminiscências deixadas por lembranças não elaboradas ou mal resolvidas. As doenças e as perdas representam duas maiores expressões da história de sujeitos somatizantes; e envolvidas em situações de conflito e de violência, se tornam condições comprometedores da capacidade de a família sustentar-se psíquica e afetivamente.

Dentre as situações significativas na história familiar, é dado destaque à própria doença, como situação marcante na história. Na família 1, a fala entre mãe e filha enfatiza esse destaque: "Eu fiquei em feridas, em feridas, que eu tenho cicatriz até hoje... É só nas pernas" (Filha).” “... nossa senhora, ela passou muita coisa" (mãe).

A convivência com um membro doente leva o grupo a pensar sobre a sua história, mesmo encontrando dificuldades de enfrentamento da própria situação. De certa forma, as situações marcantes, principalmente as de violência, perpassam as outras temáticas e promovem um desgaste emocional em todos, significando fator expressivo no processo de adoecimento de sujeitos da família.

Percebemos que histórias não contadas ou esquecidas surgem como material recalcado no discurso de sujeitos doentes e de sujeitos cuidadores, como na família 4: "meu marido mudou, adoeceu muito depois que meu filho, meu filho morreu...com 15 anos...”. A família lança mão de alguns mecanismos de defesa, nem sempre favoráveis ao grupo, pois, às vezes, operam como tentativa de sufocar algo que ainda não é possível de ser confrontado e dito. $\mathrm{O}$ trabalho de exigência de sentido sobre aquilo que não se deseja confrontar evidencia uma problemática do grupo na atualidade. Percebemos certa distância entre pensamento, sentimento e aquilo que pode ser expressado pelos membros da família. Essas situações geram tensões e impasses entre o que se quer dizer e o que é dito realmente do outro, demonstrando antes de tudo certa indiferença com as demandas subjetivas dos membros. A indiferença acarreta um distanciamento afetivo e configura um campo propício para o afloramento de situações violentas.

Nesse sentido, as somatizações surgem como uma faceta dessas violências. O adoecimento na família deve ser avaliado por uma perspectiva psicocultural considerando a história de vida e a dinâmica intra e interpsíquica do grupo. Sendo assim, a doença não é somática, mas psicossociossomática. Ela possui uma gama de significados simbólicos, morais, culturais, sociais e psicológicos interligados. A doença não é do corpo ou da alma somente; ela é de todos.

Como um último ponto, consideramos o ciclo de vida familiar. A cada fase do ciclo vital da família há novas exigências, mudanças e adaptações, o que pode representar um estopim para conflitos internos existentes. Entretanto, não conseguimos identificar se a maternidade, por exemplo, serviu de compensação ou sublimação diante das situações difíceis de doenças e perdas. Cabe ainda avançar neste aspecto, destacando em pesquisas futuras os mecanismos de superação da família, diante do sofrimento e do adoecimento.

Devemos considerar que o trabalho de prevenção e de promoção de saúde por profissionais da área pode ser iniciado com a compreensão do funcionamento familiar, assim como com o entendimento da história de vida da família. Este relato de pesquisa busca, assim, contribuir para que o lugar 
do psicólogo possa favorecer esta compreensão do universo familiar, contribuindo para a ampliação de ações à saúde da família.

\section{Referências}

Bardin, L. (2007). Análise de Conteúdo (3ª Ed.) Lisboa: Edições 70. Carter, B., \& McGoldrick, M. (Eds.). (1995). As mudanças no ciclo de vida familiar: uma estrutura para a terapia familiar ( $2^{\mathrm{a}} \mathrm{ed}$.). Porto Alegre: Artmed.

Castiel, L. D. (1994). A multiplicidade e a singularidade do humano e seu adoecer. In L. D. Castiel (Ed.), O Buraco e o Avestruz: a singularidade do adoecer humano (pp. 171-203). Campinas: Papirus.

Chazan, L. F. (2004). Trabalhando com as famílias na atenção primária. In J. F. Mello, \& M. Burd (Eds.), Família e doença (pp. 111-122). São Paulo: Casa do Psicólogo.

Coelho, C. L. S., \& Ávila, L. A. (2007). Controvérsias sobre a somatização. Revista de Psiquiatria Clínica, 34(6), 278- 284.

Déjours, C. (1989). Repressão e Subversão em Psicossomática Investigações psicanalíticas sobre o corpo. Rio de Janeiro: Jorge Zahar editor.

Féres-Carneiro, T. F. (Ed.). (2003). Família e Casal: arranjos e demandas contemporâneas. Rio de Janeiro: Editora PUC Rio.

Freud, S. (2000). A Etiologia da histeria. In J. Strachey (Ed.), Reedição das obras completas psicológicas de Sigmund Freud (vol. 3) Rio de Janeiro: Imago. (Trabalho original publicado em 1896)

Freud, S. (2000). Sobre o mecanismo psíquico dos fenômenos histéricos: uma conferência. In J. Strachey (Ed.), Reedição das obras completas psicológicas de Sigmund Freud (Vol. 3). Rio de Janeiro: Imago. (Trabalho original publicado em 1893)

Freud, S. (1978). O Mal estar na civilização. In Coleção Os pensadores. Rio de Janeiro: Imago. (Trabalho original publicado em 1930)
Freud, S. (1978). Cinco Lições de Psicanálise. In Coleção Os pensadores. Rio de Janeiro: Imago. (Trabalho original publicado em 1910)

Geertz, C. (1989). A Interpretação das culturas. Rio de Janeiro: Livros Técnicos e científicos.

Lipowski, Z. J. (1988). Somatization: The Concept and Its Clinical Application. American Journal of Psychiatry, 145, 1358-1368.

Lisboa, A. V., Santos, A. L. dos., Bassoli, F. A., Paiva, N. D., \& Fernandes, T. C. (2011). Escuta de Famílias em Domicílio: Ação do Psicólogo na Estratégia de Saúde. Psicologia: Ciência e Profissão, 31(4), 748-761.

Macedo, R. M. S. (Ed.). (2008). Terapia Familiar no Brasil na Última Década. São Paulo: Rocca.

McGoldrick, M., \& Gerson, R. (1995). Genetrogramas e o Ciclo de Vida Familiar. In B. Carter \& M. McGoldrick (Eds.), As mudanças no ciclo de vida familiar: uma estrutura para a terapia familiar (2 ed., pp. 144-166). Porto Alegre: Artmed.

Mello Filho, J., \& Burd, M. (Eds.). (2010). Psicossomática Hoje. Porto Alegre: ArtMed.

Marty, P. (1980). L'ordrepsychossomatique. Paris: Payot.

Marty, P. (1998). Mentalização e Psicossomática. São Paulo: Casa do Psicólogo.

Osório, L. C., \& Valle, M. E. P. (Eds.). (2009). Manual de Terapia Familiar. Porto Alegre: ArtMed.

Osório, L. C., \& Valle, M. E. P. (Eds.). (2011). Manual de Terapia Familiar (Vol. II). Porto Alegre: ArtMed.

Ruiz Correa, O. B. (Ed.). (2000). O Legado Familiar: a tecelagem grupal da transmissão psíquica. Rio de Janeiro: Contra Capa.

Ruiz Correa, O. B. (2002). A Intersubjetividade nos processos de transmissão psíquica geracional. Revista Trieb, 1, 145-156.

Ruiz Correa, O. B. (2007). O transgeracional na violência familiar. In O. B. Ruiz Correa (Ed.), Grupo Familiar e Psicanálise: ressonâncias clínicas (pp. 53-67). São Paulo: Vetor.

Turato, E. R. (2003). Tratado da Metodologia da Pesquisa Clínicoquantitativa ( $2^{\mathrm{a}}$ ed.). Rio de Janeiro: Vozes.

Winnicott, D. W. (1993). A Familia e o desenvolvimento Individual. São Paulo: Martins Fontes. 